\title{
ARQUITECTURA HISTOLOGICA DE LA PLACENTA HUMANA AL CONTRASTE DE FASES Y APLICACIONES CLINICAS
}

\author{
Dr. Gustavo Isaza Mejía*
}

Gloria Yepes Zapata**

Myriam Castaño S.**

El estudio de la placenta humana por medio del microscopio de contraste de fases, fue llevado a cabo y descrito por el profesor Hermógenes Alvarez de la Clínica Ginecológica del Uruguay en el año de 1964 (1).

El procedimiento, entre otras ventajas, tiene el de ser supremamente sencillo, rápido y económico, con él se pueden reconocer algunas alteraciones útiles para el diagnóstico de entidades tales como: diabetes materna, eritroblastosis fetal, sífilis, envejecimiento prematuro de la placenta, mola hidatiforme y toxemias.

Este procedimiento permite reconocer el grado de eritroblastosis fetal en pocos minutos después del nacimiento y establecer la necesidad de una exanguinotransfusión sin más demora. Inclusive los autores uruguayos han elaborado una técnica de punción placentaria que puede realizarse a partir de la $12^{\text {a }}$ semana de la gestación, en placentas implantadas en la cara anterior del útero; método por medio del cual se pueden diagnosticar las entidades mencionadas y controlar su evolución en forma sencilla y rápida.

\section{Material y Método}

Hemos estudiado macroscópicamente 1.800 placentas a término y 160 de abortos en diferentes épocas de evolución. Seleccionamos 550 para estudio microscópico directo por contraste de fases, coloración vital de Rakoff, Pananicolaou y estudio histopatológico por inclusión en parafina y coloración con Hematoxilina-Eosina.

Utilizamos la técnica descrita por los autores uruguayos con microscopio de contraste de fases y también hemos ideado otra similar valiéndonos de la coloración de Rakoff que se usa en citología funcional y se observa con el microscopio común; llegando a la conclusión de que los resultados son similares, y en ocasiones superiores.

Como las preparaciones para contraste de fases y las coloraciones vitales con Rakoff se alteran rápidamente y no se pueden conservar, he-

* Profesor Agregado de Ginecología en la Facultad de Medicina de la Universidad de Antioquia.

** Citotécnica del Instituto de Citología Exfoliativa Papanicolaou de Medellín. 
mos utilizado un sistema con fijación, deshidratación y coloración de Papanicolaou que nos suministra una imagen un poco diferente pero más real a la que se obtiene con los cortes histológicos (Figura N:1).

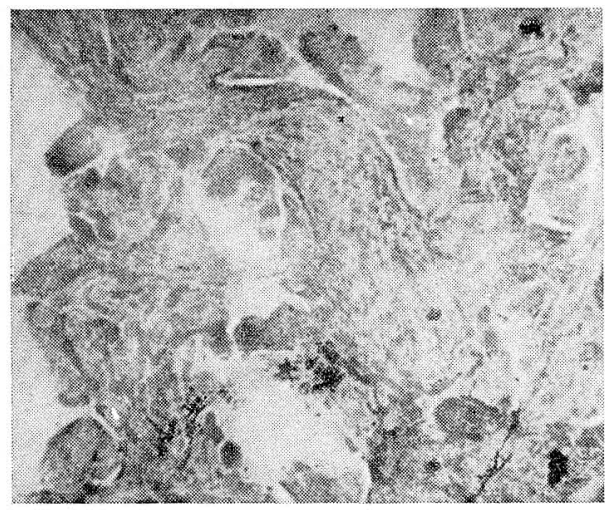

FIGURA No 1 - Placenta a término, arborización de las vellosidades Papanicolaou. X 10.

\section{Arquitectura Histológica}

Entre la cuarta y octava semana las vellosidades coriales están representadas principalmente por tallos de primer orden que se dividen sucesivamente para formar los tallos de segundo y tercer orden, dando el aspecto de gemación o brotes en una forma muy semejante a lo que sucede con la formación y crecimiento de las raíces de un árbol (Figura № 2).

En un corte histológico por el sistema común de fijación y de inclusión en parafina, observamos troncos vellositarios de diversos órdenes y las vellosidades cortadas en planos diversos. Si a ello le agregamos la deformación y encogimiento del material placentario producido por el proceso de fijación e inclusión, tendremos una imagen muy deformada de la realidad arquitectónica de la placenta. (Figura No 3).

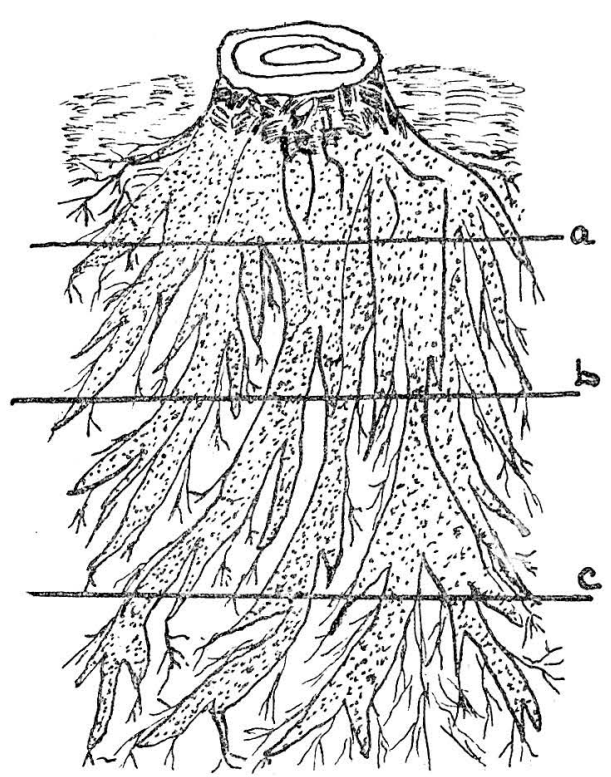

FIGURA No 2 - Raíz de un árbol: Brotes de: a) ler. orden - b) $2 x$ orden - c) 3er. orden. Esquemático.

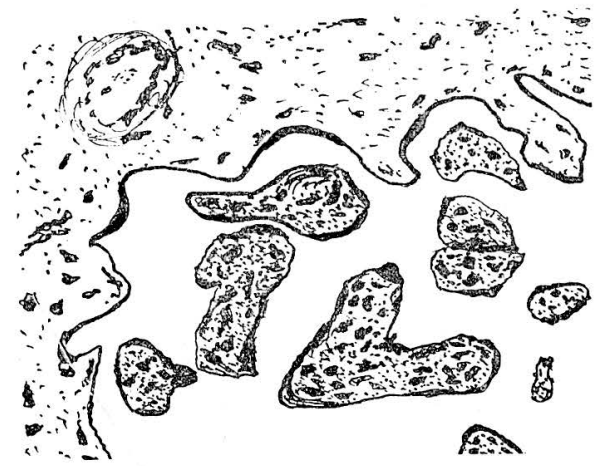

FIGURA No 3 - Placenta a término: vellosidades corladas en todas direcciones. Esquemático.

En observación directa con el contraste de fases o la coloración vital, por el contrario, tenemos una imagen exacta de lo que es la arquitectura placentaria en su estado natural, sin artificios ni deformaciones consecutivas a las manipulaciones corrientes. (Figura No 4). 


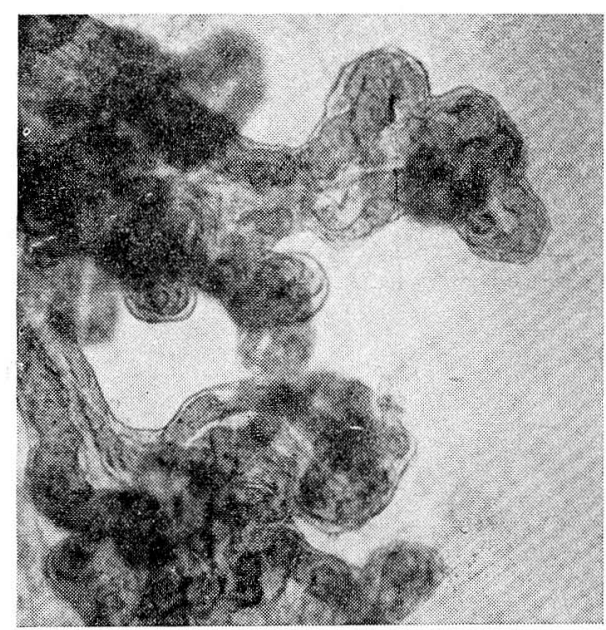

FIGURA No 4 - Placenta a término. Brotes vellositarios. Contraste de Fases.

De la séptima a la octava semana de su evolución, los tallos de tercer orden se alargan cada vez más, se ensanchan en su extremo de implantación en la placa decidual y empiezan a vascularizarse en su estroma. La vascularización avanza progresivamente para formar el estroma de los brotes neoformados cada vez más numerosos, que a su vez están revestidos por el citotrofoblasto o capa de Langhans y el Sinciciotrofoblasto siendo éste el que mejor se reconoce al contraste de fases. El citotrofoblasto se reconoce difícilmente.

En esta época el sincicio produce numerosos brotes protoplasmáticos avasculares que le dan la apariencia de un cactus, éstos brotes son cilíndricos, pediculados, dentro de los cuales pueden observarse vacuolas y a veces muy grandes; según Wislocki éstas vacuolas estarían formadas por el plasma materno que penetra a la vellosidad por el fenómeno de pinocitosis (1).

El estroma está compuesto por tejido conjuntivo muy laxo y capilares

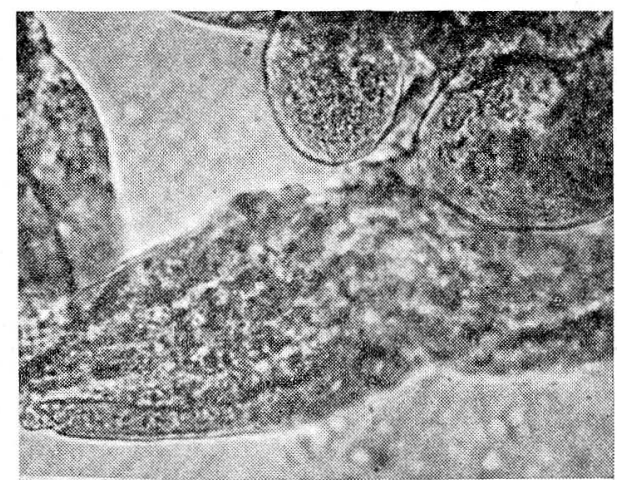

FIGURA No 5 - Placenta de 2 meses. Brotes vellositarios de diámetro amplio.

axiales rodeados por una fina red paracapilar que los comunica con el epitelio corial.

\section{Diámežro de la vellosidad}

El diámetro de las vellosidades disminuye a medida que el embarazo progresa, alcanza casi hasta $350 \mathrm{mi}-$ cras en la doceava semana; de allí en adelante decrece en forma vertical hasta llegar a 140 micras solamente. (Figs. Nos. 4 y 5 ).

El sinsiciotrofoblasto tiene una gran capacidad para formar brotes en la placenta de las primeras etapas del crecimiento; al final del embarazo normal, esta capacidad disminuye; para aparecer nuevamente en los casos de hipoxia y otras anomalías como defectos de implantación y disminución del aflujo sanguíneo (1).

Según Wislocki y Bempsey (2), las vacuolas del epitelio sincicial presentan características tales como reacción de Shiff fuertemente positiva, son birrefrigentes, lo cual las asemeja a las vacuolas cargadas de esteroides de la zona fasciculada y glomerular de las cápsulas suprarrenales, a las de la teca interna y al cuerpo lú- 
teo del ovario; este fenómeno ha sido interpretado por Alvarez y colaboradores (3) como la prueba de que la formación de esteroides es de temprana aparición en la placenta y actúa como una adición a los producidos por el cuerpo lúteo del ovario, utilizables en la nidación y continuación del embarazo. Esto explicaría claramente la preservación del embarazo en aquellos casos de extirpación del cuerpo lúteo, no siendo necesario responsabilizar de esta función a los esteroides de las suprarrenales. La placenta por sí sola, está en condiciones de producir los esteroides que se requieren para preservar y llevar a cabo la evolución normal del embarazo.

La temprana desaparición o ausencia de las vacuolas nos permite hacer el diagnóstico de insuficiencia placentaria lo cual encontraron Alvarez y colaboradores en un $42,6 \%$ de los abortos de las primeras semanas en casos de insuficiencia endocrina. Por el contrario la presencia de vacuolas en cantidad normal, nos serviría como signo para el diagnóstico del aborto provocado artificialmente.

\section{Aplicaciones del método}

El estudio de las vellosidades coriales por medio del contraste de fases, nos permite llevar a cabo en pocos minutos el diagnóstico de algunas entidades que afectan al embarazo, en el momento mismo del parto o mejor aún In Utero, por el método de biopsia por aspiración de la placenta, y nos servirá para establecer tratamientos y llevar a cabo ciertas conductas: el aborto terapéutico, la inducción del parto con un criterio histológico suficiente y adecuado en casos de: toxemia, diabetes, eritroblastosis, sífilis y mola hidatiforme.

\section{Toxemia}

Siempre que hay hipoxia, aparece una hiperplasia de los brotes vellositarios.

Según Alvarez y colaboradores, la placenta de la toxémica se rejuvenece, hiperplasia, es todo lo contrario del viejo concepto y que se repite aún en libros y revistas.

La presencia de lesioness vasculares en las vellosidades de las toxémicas, indican el fenómeno de la hipoxia y como consecuencia su tratamiento debe ser con vaso-dilatadores, si tenemos en cuenta que la oxigenación del feto se hace a través de la membrana sincicio-vascular y que en la toxemia al aumentar el trofoblasto por su hiperplasia, entonces tendrá que disminuir lógicamente el aporte de oxígeno y de allí el sufrimiento crónico del feto. La placenta al rejuvenecerse por el aumento de brotes del sinciciotrofoblasto disminuye la superficie o membrana sincicio-vascular, por lo tanto no es un mecanismo de defensa.

En Diabetes y Sífilis se observa edema de la vellosidad y nos sirve para control del tratamiento.

En la Eritroblastosis. El edema de la vellosidad y la gravedad de la enfermedad tienen una relación directa $y$ es por lo tanto de un gran valor pronóstico. Alvarez y colaboradores del Uruguay clasifican el edema de la vellosidad en tres grados: I, II, III lo cual sirve de guía en la conducta que se ha de seguir. El grado del edema nos permite hacer el diagnóstico de la eritroblastosis y su grado de intensidad en forma segura y rápida (algunos minutos). El edema se puede reconocer In Utero haciendo la punción biopsia placentaria. 


\section{Comentarios}

Se presenta un método práctico y rápido para estudiar y diagnosticar algunas entidades patológicas del complejo ovofeto, método éste desarrollado en la escuela uruguaya por el profesor Hermógenes Alvarez. Consiste en hacer una observación del material placentario sin coloración por medio del microscopio de contraste de fases. Hemos hecho una modificación preparando el material de estudio con una gota de colorante de Rakoff y observarlo con el microscopio de luz.

Creemos que los datos o hallazgos normales y los patológicos son similares: El método con colorante de Rakoff tiene la ventaja de que no necesita microscopio especial es muy fácil de realizar por el médico en cualquier lugar y no requiere conocimientos o entrenamiento previo en histopatología.

Por este sistema podemos en pocos minutos reconocer los abortos verdaderos de otras entidades que lo simulan especialmente en las primeras semanas.

La punción biopsia placentaria In Utero, nos permite controlar la evolución del tratamiento en la diabetes y Lúes. En la eritroblastosis nos permite reconocer la gravedad de la enfermedad hemolítica, la evolución y el pronóstico con mucha mayor seguridad que la prueba de Coombs, y tomar decisiones en relación con el parto en casos de sufrimiento fetal $y$ embarazo prolongado.

\section{Conclusiones}

1. El estudio directo de las vellosidades coriales por medio del contraste de fases es de gran utilidad en el diagnóstico y evolución de algunas entidades patológicas: Diabetes, sífi- lis, eritroblastosis, mola hidatiforme $y$ toxemias.

2. Permite reconocer la evolución de la enfermedad hemolítica con mayor certeza que la prueba de Coombs.

3. La modificación llevada a cabo por nosotros: estudio directo con coloración vital de Rakoff, usando el microscopio común dá resultados similares al contraste de fases.

4. El mayor mérito del sistema propuesto, estriba en su sencillez, seguridad y rapidez.

5. Toda placenta a término y de aborto debe ser sometida a examen. La cuidadosa observación macro y microscópica, puede aportar mucha luz en los problemas del embarazo y aborto.

\section{Summary}

1. Direct study of corial hairiness by phase contrast is very useful for diagnosis and evolution of some pathological entities: diabetes, syphillis, erythroblastosis, hydatiform moel and toxemias.

2. It is more accurate than Coomb's test for following the evolution of hemolytical disease.

3. We made a modification: direct study with vital Rakoff dye, using a regular microscope; with similar results to the phase contrast.

4. The merit of the proposed system is its simplicity, security and speed.

5. Every placenta, both from delivery and from abortion, should be examined. Careful macroscopical and microscopical observation can bring light into many pregnancy and abortion problems. 


\section{BIBLIOGRAFIA}

1 ALVAREZ hermogenes. M. D.: "Morphology and physiopathology of the Human Placenta". Obst-Gynecology. Vol. 23. 813, 1964.

2 WISLOCKI, G. B. and DEMPSEY, E. W. The chemical histology of human placenta and
Rev. Col. Obst. y Ginec.

decidua with reference to mucoproteins, glicogen, lipids and phosphatasa. Am. J. Anat. 83: $1,1948$.

3 ALVAREZ, H., DE BEJAR, R., and ALVAREZ SANTIN, C. Aborto e inmadurez fetal. Arch. Ginecology Obst. (Uruguay). 20: 58, 1962. 